\title{
Efficacy of nurse-led cardiac rehabilitation on health care behaviours in adults with chronic heart failure: An experimental design
}

\author{
Porkodi Arjunan a , Melba Sheila D'Souza ${ }^{\text {b, }}$ \\ ${ }^{a}$ Faculty of Nursing, Sri Ramachandra Institute of Higher Education and Research, Chennai, India \\ ${ }^{\mathrm{b}}$ School of Nursing, Thompson Rivers University, British Columbia, V2C0C8, Canada
}

\section{A R T I C L E I N F O}

\section{Keywords:}

Health care behaviours

Adherence

Cardiac rehabilitation

Heart failure

Nursing

\begin{abstract}
A B S T R A C T
Introduction: Nonadherence and poor health care behaviors contribute to worsening of heart failure symptoms, in many cases leading to increased morbidity and mortality.

Aim: To assess the efficacy of nurse-led cardiac rehabilitation on health care behaviours in adults with chronic heart failure. Method. An experimental design was conducted in India from January to December of 2019. A sample size of 200 adults with heart failure from a tertiary cardiac care center was enrolled. Participants were allocated into an intervention group $(n=100)$ and a control group $(n=100)$. A nurse-led cardiac rehabilitation program using a virtual educational video and reminder telephone calls was given to the intervention group for six months. A modified heart failure adherence and health care behaviours scale was used.

Results: $78 \%$ of the adults in the intervention group and $79 \%$ of the adults in the control group were males. $43 \%$ of the adults in the intervention group and $32 \%$ of the adults in the control group had $\geq 2$ years of chronic heart failure. $42.27 \%$ of the participants in the intervention group and $35.05 \%$ of the adults in the control group indicated that medical follow-ups were essential. $21.65 \%$ of the adults in the intervention group and $13.40 \%$ of the adults in the control group expressed no difficulty adhering to the sodium restriction in the posttest2. The participants in the intervention group had higher health care behaviours compared to control group, $\mathrm{p}<0.001$. Conclusion/Implication: Cardiac nurses need to adopt cardiac rehabilitation in continuity of care for improving health care behaviours for adults with chronic heart failure.
\end{abstract}

\section{Introduction}

The prevalence of the cardiovascular disease is on the rise, and it is also a leading cause of death in India. Chronic heart failure (CHF) is a progressive syndrome with high morbidity and mortality despite recent improvements to its treatment. ${ }^{1}$ Overall, it appears that CHF affects $1-3 \%$ of the general population and $10 \%$ of the older adults. ${ }^{2}$ Estimates of CHF prevalence in the Asia region range from $1.26 \%$ to $6.7 \% .{ }^{3}$ Nearly 6.5 million people in Europe, 5 million people in the USA, and 2.4 million people in Japan diagnosed with CHF. In China, 4.2 million people have CHF, whereas in India, between 1.3 and 23 million, and in Southeast Asia, 9 million people have been estimated to have $\mathrm{CHF}^{4-6}$ Ischemic heart disease is the primary cause of CHF in the Asia-Pacific populations (27\%-48\%) and the Western populations (40\%-58\%). ${ }^{7-9}$ The comorbidities such as hypertension and diabetes were highly prevalent in Asian patients with CHF. ${ }^{8,10} \mathrm{CHF}$ is a chronic progressive disease with the patient experiencing declining heart functions and more frequent episodes of failure leading to low tissue perfusion. ${ }^{11,12}$

Adults with complex comorbidities, higher body mass index have a significantly lower quality of life, physical functioning, role-physical, body pain, role-emotional, emotional wellbeing. ${ }^{13}$ Poor adherence and imperfect recollection of prescribed medication have been associated with a higher frequency of hospitalization in elderly patients. ${ }^{14}$ Positive self-care behaviours were correlated with higher income, higher education, lower body weight, and higher awareness of self-management. ${ }^{15}$ Behavioural factors such as nonadherence and delay in seeking care may contribute to readmissions and mortality. ${ }^{16,17}$ Barriers and facilitators to health care behaviours are highly related to nonadherence and health literacy. ${ }^{18}$ The prognosis seems inadequate among adults with CHF because of depression, psychosocial or behavioural deficits. ${ }^{19}$ Patients are at risk for readmissions and complications due to a lack of knowledge and social support. ${ }^{20}$

Health care behaviours are fundamental to life style modifications for maintaining the quality of life among adults with $\mathrm{CHF}^{21,22}$

\footnotetext{
* Corresponding author.

E-mail addresses: porkodi@sriramachandra.edu.in (P. Arjunan), mdsouza@tru.ca (M.S. D’Souza).
} 
Self-efficacy and self-confidence increases the confidence in adults in self-care behaviours, while nonadherence is a significant barrier to self-efficacy. ${ }^{23}$ Adults with CHF are expected to adhere with self-care behaviours like maintaining follow-ups, medications, weight checking behaviour, exercise, and lifestyle modification. Lifestyle modifications improve the treatment plan and prognosis of patients with heart failure. ${ }^{24}$ Educating patients about CHF treatment and the consequences of $\mathrm{CHF}$ has been shown to improve health care behaviours. ${ }^{25}$ While medical treatment plans vary according to each stage of the disease, lifestyle changes such as smoking cessation, regular exercise, reduced alcohol intake are recommended strategies regardless of the stage of $\mathrm{CHF}^{26,27}$ Daily consumption of 2-3 $\mathrm{g}$ of sodium in the CHF population, depending on CHF severity, is recommended. ${ }^{28}$ Health care behaviours will be better improved if the nurses are planning and informing specific health promotion strategies along with decision making of the adults with CHF. A tailored educational program for adults contributes to better self-care and self-care management towards promoting quality of life. This emphasizes the importance of directing a nurse-led cardiac rehabilitation for adults with CHF to improve their health care behaviours and adherence. The aim of the study is to assess the efficacy of nurse-led cardiac rehabilitation on health care behaviours in adults with chronic heart failure.

\section{Methods}

\subsection{Research design and approach}

An experimental research design was used to evaluate the efficacy of nurse-led cardiac rehabilitation on health care behaviours in adults with chronic heart failure.

\subsection{Ethics considerations}

An institutional ethics approval and certificate was obtained from Sri Ramachandra Institute of Higher Education and Research with reference to IEC/07/21/Nov/2018. A written and verbal informed consent was obtained from the adults recruited in the study. Confidentiality and privacy for ensured for the participants. Participants could withdraw from the study at any time during and after the study without any consequences to clinical outcomes and health care.

\subsection{Nurse-led cardiac rehabilitation program}

The nurse-led cardiac rehabilitation program (NLCRP) for chronic heart failure was developed based on the hospital and national cardiac rehabilitation guidelines and tailored to the participant's cultural values, preferences, review of literature, and consultants' feedback. The NLCRP educational and practice components included recommendations on diet, exercise, medication, weight checking, smoking cessation, sodium restriction, fluid restriction, and lifestyle modification. An individual discussion with creative thinking and problem solving were used to deliver the cardiac rehabilitation to the intervention group. The virtual educational video on cardiac rehabilitation components was used to teach adults with CHF on an individual session for $3 \mathrm{~h}$ over five days (total of $15 \mathrm{~h}$ ). A virtual educational video was created titled 'Healthy way to a Healthy Heart' focused on the educational and practice components to tailor to the needs of the adults in the intervention group. The virtual educational video was delivered to the participants after transition to home care. The NLCRP was validated by two cardiac clinical specialty nurses and one cardiac physician to finalize the NLCRP.

The researcher made a follow-up reminder telephone calls every fortnight (every 15 days) for a consecutive six months using a structured motivational interviewing. The motivational interviewing protocol consisted of check ins for appointment keeping, treatment adherence, exercise regimen, home care, active living, and lifestyle modification for reinforcement and adherence to a cardiac rehabilitation program after discharge from the hospital. The control group was provided with the usual care, and standard discharge advise about prevention and care with chronic heart failure in the hospital. The pretest was done at baseline, posttest 1 at the end of 3 months and posttest 2 at the end of 6 months for intervention and control group.

\subsection{Participants and setting}

This study was conducted in a Sri Ramachandra Institute of Higher Education and Research cardiology clinical unit, a multispecialty tertiary hospital in India. Adults were recruited from the clinical cardiology center which included a coronary care, cardiothoracic intensive, cardiology, cardiac care, and rapid access units. The target population was adults diagnosed, treated, and managed for chronic heart failure and admitted to the cardiology clinical unit from 1 January to 30 December 2019. The participants were recruited based on the eligibility criteria: adults diagnosed to have chronic heart failure (coronary artery disease, dilated cardiomyopathy, or hypertensive heart disease), an ejection fraction $\leq 40 \%$, New York Heart Association classification of Dyspnea Grade II and III and above 30 years. The exclusion criteria included cardiac surgery complications like a cerebrovascular accident, end-stage renal or liver disease and palliative care.

\subsection{Recruitment and sampling}

The sample size was calculated at 180 with a power of $80 \%$ at a level of significance of $0.05 .{ }^{29}$ With a $10 \%$ attrition rate, a sample size of 200 was recruited, with 100 in each group. A simple random sampling was used with a lottery method to recruit the participants for this study. Two hundred adults were randomly assigned to the intervention group and control group using computer-generated block randomization. The intervention and control groups were affixed to 10 blocks each, and the 20 blocks were sealed individually in sequentially numbered. The opaque envelopes containing blocks were picked up from the box by the participants. The researchers, participants, and nurses were blinded to group assignments. One hundred participants were assigned to the intervention group and 100 participants were assigned to control group.

\subsection{Measurements and outcomes}

Modified heart failure compliance scale: Primary outcomes were adherence and healthcare behaviors of participants with choric heart failure. To assess the level of adherence, a standardized heart failure adherence and health care behaviours (AHCB) scale was used that comprised of 30 items. ${ }^{30,31}$ The AHCB scale was validated and modified, adding ten more items by the investigators. The modified heart failure AHCB scale has eight health behaviour components: appointment-keeping, medication, sodium restriction, fluid restriction, daily weighing, exercise, smoking cessation, and lifestyle modification. The modified heart failure AHCB scale is a self-administered questionnaire that consists of 40 items on a 5-point Likert scale. The tool was used to rate the difficulty in adherence to identify the barriers for adherence and the level of adherence for various health behaviour components. Patients were informed to state how important the health behaviour was by using a 5-point scale ranging from 0-Not at all critical, 1-Somewhat important, 2-Important, 3-Very important, and 4-Highly important. Adults were asked to identify whether they had difficulty in complying with the health care behaviour. Adherence was measured on a 5-point Likert scale: 0-None of the time, 1-Very seldom, 2-About half of the time, 3-Most of the time, and 4-All. Adults were asked to rate their adherence to the health care behaviour when they come for the follow-up to the hospital. Patients were asked to rate their level of difficulty in adherence to health behaviour. It was measured on a four-point scale, 0-No difficulty, 1-A little difficulty, 2-Moderate difficulty, and 3-A lot of difficulty. Adults were asked to express the barriers 
to adherence to cardiac rehabilitation. Permission was obtained to use the standardized heart failure adherence and health care behaviours for the participants. Adults have grouped either adherent if they had been complying with health behaviour always/most of the time or non-adherent if they had been complying with health behaviour half of the time, seldom or never. Adults were considered overall adherent when they were compliant with six or more of the eight specific health behaviour recommendations. Adults were considered non-adherent when they were compliant with five or less of the eight specific recommendations. The AHCB scale was validated by two cardiac clinical specialty nurses and one cardiac physician. The test-retest reliability of the modified heart failure compliance scale using the intraclass correlation coefficient was found to be 0.79 .

The demographic and clinical measures were age, gender, education, occupation, residence, income, duration of illness, medical diagnosis, comorbidities, complexity, continuity of care, and home care supports.

\subsection{Analysis}

Statistical package for social science version 25.0 (IBM Corp. Armonk, NY) was used to analyze the data. Paired ' $t$ ' test and ANOVA was used to analyze the data, $\mathrm{p}<0.05$ was accepted as a statistically significant. Anonymity of data and data security was ensured in the study.

\section{Results}

\subsection{Demographic and clinical characteristics}

$65 \%$ of the adults with chronic heart failure were in the intervention group, and $66 \%$ of the adults were in the control group (Table 1). 50\% and $41 \%$ of the adults lived in the urban places in the intervention and control groups, respectively (Table 1). Clinical characteristics: $43 \%$ of the adults who had more than two years lived with chronic heart failure in the intervention group, and $32 \%$ of the adults over two years were in the control group (Table 1).

\subsection{Efficacy of nurse-led cardiac rehabilitation adherence}

Intervention group: The postest 1 mean score was $\mathrm{x}^{-}=3.89 \pm 1.814$ after the intervention of structured teaching program, which was significantly increased $(\mathrm{p}<0.000)$ with a mean difference of 0.840 (Table 2). The postest 2 mean score and the mean difference was 1.289 from posttest 1 to posttest two was significantly higher $(\mathrm{p}<0.000)$ (Table 2).

Control group: The mean difference in the pretest to posttest 1 was 0.69 ( $\mathrm{p}<0.000$ ) (Table 2). There was no significant difference and mean difference $(0.196)$ in the posttest 1 to the posttest $2(P=0.203)$ in the control group (Table 2).

\subsection{Efficacy to adherence}

The pretest mean difference was 0.680 between the intervention and the control group $(\mathrm{P}<0.002)$ (Table 3$)$. posttest1 and posttest2 had a high mean difference of $0.830(\mathrm{p}<0.001)$ and $0.876(\mathrm{P}<0.000)$, respectively, between the intervention and control group (Table 3 ).

The mean score in pretest $\left(\mathrm{x}^{-}=3.01 \pm 1.381\right)$, posttest $1\left(\mathrm{x}^{-}=3.89 \pm\right.$ $1.83)$ and posttest $2\left(\mathrm{x}^{-}=4.18 \pm 1.041\right)$ was statistically significant for the intervention group $(\mathrm{p}<0.004)$ compared to the control group $\left(\mathrm{x}^{-}=\right.$ 2.39, 3.1, and 3.3) (Table 4).

\subsection{Efficacy of healthcare behaviors}

In the pretest, majority of the participants in the intervention group were non-adherent with regard to appointment keeping, medication, weight checking, sodium restriction, fluid restriction, exercise, smoking
Table 1

Demographic and clinical characteristics of participants in intervention and control group.

\begin{tabular}{|c|c|c|}
\hline Characteristics & $\begin{array}{l}\text { Intervention }(\mathrm{n}=100) \mathrm{F} \\
(\%)\end{array}$ & $\begin{array}{l}\text { Control group }(n=100) F \\
(\%)\end{array}$ \\
\hline \multicolumn{3}{|l|}{ Demographic characteristics } \\
\hline \multicolumn{3}{|l|}{ Age } \\
\hline $31-50$ years & $22(22 \%)$ & $17(17 \%)$ \\
\hline $51-70$ years & $65(65 \%)$ & $66(66 \%)$ \\
\hline Above 70 years & $13(13 \%)$ & $17(17 \%)$ \\
\hline \multicolumn{3}{|l|}{ Gender } \\
\hline Male & $78(78 \%)$ & $79(79 \%)$ \\
\hline Female & $22(22 \%)$ & $21(21 \%)$ \\
\hline \multicolumn{3}{|l|}{ Level of education } \\
\hline No education & $14(14 \%)$ & $10(10 \%)$ \\
\hline Primary school & $23(23 \%)$ & $22(22 \%)$ \\
\hline High school & $45(45 \%)$ & $49(49 \%)$ \\
\hline Collegiate & $18(18 \%)$ & $19(19 \%)$ \\
\hline \multicolumn{3}{|l|}{ Occupation } \\
\hline Skilled & $44(44 \%)$ & $45(45 \%)$ \\
\hline Professional & $21(21 \%)$ & $20(20 \%)$ \\
\hline Retired & $35(35 \%)$ & $35(35 \%)$ \\
\hline \multicolumn{3}{|l|}{ Living residence } \\
\hline Urban & $50(50 \%)$ & $41(41 \%)$ \\
\hline Rural & $19(19 \%)$ & $25(25 \%)$ \\
\hline Semi Urban & $31(31 \%)$ & $34(34 \%)$ \\
\hline \multicolumn{3}{|c|}{ Monthly family income (USD) } \\
\hline$<59.35$ USD & $41(41 \%)$ & $22(22 \%)$ \\
\hline 59.36-89.02 USD & $21(21 \%)$ & $23(23 \%)$ \\
\hline 89.03-118.70 USD & $13(13 \%)$ & $21(21 \%)$ \\
\hline$>118.70$ USD & $25(25 \%)$ & $34(34 \%)$ \\
\hline \multicolumn{3}{|l|}{ Clinical characteristics } \\
\hline \multicolumn{3}{|l|}{ Duration of heart failure } \\
\hline$<6$ months & $23(23 \%)$ & $21(21 \%)$ \\
\hline 6 months -1 year & $12(12 \%)$ & $15(15 \%)$ \\
\hline $1-2$ years & $22(22 \%)$ & $32(32 \%)$ \\
\hline$>2$ years & $43(43 \%)$ & $32(32 \%)$ \\
\hline \multicolumn{3}{|c|}{ Confirmed medical diagnosis } \\
\hline Dilated cardiomyopathy & $17(17 \%)$ & $9(9 \%)$ \\
\hline $\begin{array}{l}\text { Hypertensive heart } \\
\text { disease }\end{array}$ & $5(5 \%)$ & $16(16 \%)$ \\
\hline Coronary artery disease & $78(78 \%)$ & $75(75 \%)$ \\
\hline \multicolumn{3}{|l|}{ Co-morbidities present } \\
\hline Yes & $74(74 \%)$ & $85(85 \%)$ \\
\hline No & $26(26 \%)$ & $15(15 \%)$ \\
\hline
\end{tabular}

Table 2

Efficacy of nurse-led cardiac rehabilitation adherence in the intervention and control group.

\begin{tabular}{|c|c|c|c|c|c|}
\hline \multirow[t]{2}{*}{$\begin{array}{l}\text { Time } \\
\text { intervals }\end{array}$} & \multicolumn{2}{|c|}{$\begin{array}{l}\text { Cardiac } \\
\text { rehabilitation } \\
\text { adherence score }\end{array}$} & \multirow[t]{2}{*}{$\begin{array}{l}\text { Mean } \\
\text { difference }\end{array}$} & \multirow[t]{2}{*}{$\begin{array}{l}\text { Paired ' } \mathrm{t} \text { ' } \\
\text { test value }\end{array}$} & \multirow[t]{2}{*}{$\begin{array}{l}\mathrm{p} \text { value, } \\
\text { significant***}\end{array}$} \\
\hline & Mean & $\begin{array}{l}\text { Standard } \\
\text { deviation }\end{array}$ & & & \\
\hline \multicolumn{6}{|c|}{ Intervention Group $N=100$} \\
\hline Pretest & 3.05 & 1.445 & 0.840 & 4.071 & 0.000 \\
\hline Posttest1 & 3.89 & 1.814 & & & $* * *$ \\
\hline Pretest & 3.01 & 1.381 & 1.165 & 8.588 & 0.000 \\
\hline Posttest2 & 4.18 & 1.041 & & & $* * *$ \\
\hline Posttest1 & 3.89 & 1.836 & 1.289 & 1.414 & $0.000^{* * *}$ \\
\hline Posttest2 & 4.18 & 1.041 & & & \\
\hline \multicolumn{6}{|c|}{ Control Group N = 100} \\
\hline Pretest & 2.37 & 1.574 & 0.690 & 4.963 & 0.000 \\
\hline Posttest1 & 3.06 & 1.556 & & & $* * *$ \\
\hline Pretest & 2.39 & 1.585 & 0.907 & 5.346 & 0.000 \\
\hline Posttest2 & 3.30 & 1.459 & & & $* * *$ \\
\hline Posttest1 & 3.10 & 1.531 & 0.196 & 1.282 & 0.203 \\
\hline Posttest2 & 3.30 & 1.459 & & & \\
\hline
\end{tabular}

cessation and lifestyle modification (Table 5). Most of the participants in the intervention group were adherent with regard to appointment keeping, medication, weight checking, sodium restriction, fluid restriction, exercise, smoking cessation and lifestyle modification in posttest2 
Table 3

Efficacy to nurse-led cardiac rehabilitation adherence between intervention and control group.

\begin{tabular}{|c|c|c|c|c|c|c|c|}
\hline \multirow[t]{2}{*}{ Time intervals } & \multicolumn{2}{|c|}{ Intervention group $(n=100)$} & \multicolumn{2}{|c|}{ Control group $(\mathrm{n}=100)$} & \multirow[t]{2}{*}{ Mean difference } & \multirow[t]{2}{*}{ ' $\mathrm{t}$ ' test value } & \multirow[t]{2}{*}{$\mathrm{p}$ value, significant ${ }^{* * *}$} \\
\hline & Mean & Standard deviation & Mean & Standard deviation & & & \\
\hline Pretest & 3.05 & 1.44 & 2.37 & 1.574 & 0.680 & 3.182 & $\begin{array}{l}0.002 \\
* * *\end{array}$ \\
\hline Posttest1 & 3.89 & 1.814 & 3.06 & 1.556 & 0.830 & 3.473 & $\begin{array}{l}0.001 \\
* * *\end{array}$ \\
\hline Posttest2 & 4.18 & 1.041 & 3.30 & 1.459 & 0.876 & 4.816 & $\begin{array}{l}0.000 \\
* * *\end{array}$ \\
\hline
\end{tabular}

Table 4

Repeated measures ANOVA to nurse-led cardiac rehabilitation adherence among intervention and control group.

\begin{tabular}{|c|c|c|c|c|c|c|c|c|}
\hline \multirow[t]{2}{*}{ Group } & \multicolumn{2}{|c|}{ Pretest } & \multicolumn{2}{|c|}{ Posttest1 } & \multicolumn{2}{|c|}{ Posttest2 } & \multirow{2}{*}{$\begin{array}{l}\mathrm{F} \\
\text { Value }\end{array}$} & \multirow[t]{2}{*}{ P value, significant* } \\
\hline & Mean & Standard deviation & Mean & Standard deviation & Mean & Standard deviation & & \\
\hline Intervention group & 3.01 & 1.381 & 3.89 & 1.83 & 4.18 & 1.041 & 0.595 & $0.004 *$ \\
\hline Control group & 2.39 & 1.585 & 3.10 & 1.531 & 3.30 & 1.459 & & \\
\hline
\end{tabular}

Table 5

Distribution of health care behaviors to cardiac rehabilitation adherence to intervention and control groups.

\begin{tabular}{|c|c|c|c|c|c|c|c|c|c|c|c|c|}
\hline \multirow[t]{3}{*}{ Health Care Behaviours } & \multicolumn{6}{|c|}{ Cardiac Rehabilitation Adherence } & \multicolumn{6}{|c|}{ Cardiac Rehabilitation Non-adherence } \\
\hline & \multicolumn{2}{|c|}{ Pretest } & \multicolumn{2}{|c|}{ Posttest1 } & \multicolumn{2}{|c|}{ Posttest2 } & \multicolumn{2}{|c|}{ Pretest } & \multicolumn{2}{|c|}{ Posttest1 } & \multicolumn{2}{|c|}{ Posttest2 } \\
\hline & $\mathrm{F}$ & $\%$ & $\mathrm{~F}$ & $\%$ & $\mathrm{~F}$ & $\%$ & $\mathrm{~F}$ & $\%$ & $\mathrm{~F}$ & $\%$ & $\mathrm{~F}$ & $\%$ \\
\hline \multicolumn{13}{|c|}{ Intervention Group $\mathrm{N}=100$} \\
\hline Appointment keeping & 35 & 35 & 41 & 41 & 65 & 67 & 65 & 65 & 59 & 59 & 32 & 33 \\
\hline Medication & 64 & 64 & 82 & 82 & 90 & 92.8 & 36 & 36 & 18 & 18 & 7 & 7.2 \\
\hline Weight checking & 12 & 12 & 13 & 13 & 23 & 23.7 & 88 & 88 & 87 & 87 & 74 & 76.3 \\
\hline Sodium restriction & 56 & 56 & 65 & 65 & 74 & 76.3 & 44 & 44 & 35 & 35 & 23 & 23.7 \\
\hline Fluid restriction & 36 & 36 & 55 & 55 & 77 & 79.4 & 64 & 64 & 45 & 45 & 20 & 20.6 \\
\hline Exercise & 9 & 9 & 22 & 22 & 32 & 33 & 91 & 91 & 78 & 78 & 65 & 67 \\
\hline Smoking cessation & 85 & 85 & 90 & 90 & 97 & 100 & 15 & 15 & 10 & 10 & 00 & 0.0 \\
\hline Lifestyle modification & 4 & 4 & 13 & 13 & 23 & 23.7 & 96 & 96 & 84 & 84 & 74 & 76.3 \\
\hline \multicolumn{13}{|l|}{ Control Group $N=100$} \\
\hline Appointment keeping & 23 & 23 & 25 & 25 & 33 & 34 & 77 & 77 & 75 & 75 & 64 & 66 \\
\hline Medication & 42 & 42 & 70 & 70 & 78 & 80.4 & 58 & 58 & 30 & 30 & 19 & 19.6 \\
\hline Weight checking & 6 & 6 & 4 & 4 & 3 & 3.1 & 94 & 94 & 96 & 96 & 94 & 96.9 \\
\hline Sodium restriction & 44 & 44 & 56 & 56 & 56 & 57.7 & 56 & 56 & 44 & 44 & 41 & 42.3 \\
\hline Fluid restriction & 28 & 28 & 50 & 50 & 47 & 48.5 & 72 & 72 & 50 & 50 & 50 & 51.5 \\
\hline Exercise & 10 & 10 & 18 & 18 & 12 & 12.4 & 90 & 90 & 82 & 82 & 85 & 87.6 \\
\hline Smoking cessation & 74 & 74 & 79 & 79 & 84 & 86.6 & 26 & 26 & 21 & 21 & 13 & 13.4 \\
\hline Lifestyle modification & 10 & 10 & 4 & 4 & 7 & 7.2 & 90 & 90 & 96 & 96 & 90 & 92.8 \\
\hline
\end{tabular}

(Table 5). Majority of the participants in the control group were nonadherent with appointment keeping, weight checking, fluid restriction, exercise and lifestyle modification, whereas most of the participants were adherent with medication and smoking cessation (Table 5).

\section{Discussion}

The results revealed the nurse-led cardiac rehabilitation had improved appointment keeping, medications, weight checking, sodium restriction, fluid restriction, exercise, smoking cessation, and lifestyle modifications in the postest 1 and posttest 2 for adults in the intervention group. This means there were better efficacy of adherence and health care behaviours in the intervention group. The components of the health care behaviours in the intervention group gradually increased from pretest to posttest 1 and postest 2 . This suggests that the nurse-led cardiac rehabilitation program of 3 months and 6 months was helpful to improve the health care behaviours and adherence in adults with chronic heart failure. The adults who received only routine or usual care in the control group experienced a status quo or a minor change in appointment keeping, medications, weight checking, sodium restriction, fluid restriction, exercise, smoking cessation, and lifestyle modifications from Pretest postest 1 and posttest2. Adults with diabetes mellitus exposed to telephone counselling and the structured had lower body mass index, blood glucose, and cholesterol levels leading to a better quality of life. ${ }^{32}$ Other studies show that compliance with medication and appointment keeping was higher than compliance with diet, fluid restriction, exercise and weighing with patient education. ${ }^{33,34}$

The nurse-led cardiac rehabilitation program was statistically and clinically significant for efficacy and adherence scores from posttest1 to posttest2 in the intervention group. This suggests a need to enhance strategies to improve appointment keeping, medications, weight checking, sodium restriction, fluid restriction, exercise, smoking cessation, and lifestyle modifications in chronic heart failure. Adults who received the nurse-led cardiac rehabilitation enhanced their self-efficacy with chronic heart failure to improve their activities of daily living and continuity of care. Most adults with chronic illness have poor self-care behaviours (20.6\%) and a low level of self-efficacy (31.3\%), leading to decreased quality of life. ${ }^{35}$ Adults with heart failure expressed better self-esteem and confidence with interventional therapies. ${ }^{36,37}$

No significant difference was found in sodium and fluid restrictions compliance, whereas exercise performance increased, which was statistically significant at $\mathrm{p}<0.01$. Other studies showed that initially, $63 \%$ monitored their weight only at the medical visit and $21 \%$ monitored at least once a week. ${ }^{33,38}$ More prolonged illness and higher comorbidities 
increased the risk of morbidity in heart failure. ${ }^{38,39}$ The control group had adherence only to medication, sodium and fluid restriction and smoking cessation components of cardiac rehabilitation in the Pretest and posttest2. Virtual educational videos and reminder telephone calls helped to improve the adherence for adults with CHF and can contribute to better health care behaviors. Adherence is an important factor affecting health care behaviours for adults with CHF.

The study observed a significant increase in adherence after participating in the cardiac rehabilitation in posttest1 and posttest2; the intervention group mean score. There was a significant increase in the mean scores of adherences at posttest 1 and posttest 2 ; the outcomes revealed that cardiac rehabilitation was significantly effective on adherence scores among the adults in the intervention group than the control group. Another study supported that adherence to exercise was good during supervised training but reduced during home-based training. ${ }^{33,40}$ After nine months of the study, there was a slight improvement, suggesting that supervision and support are required for these patients. Hence, the nurse-led rehabilitation positively affected physical and mental health care behaviours in adults with kidney disease. $^{41}$

\section{Limitations}

The adults were selected from a single cardiac setting and did not gather data on self-efficacy, emotional and psychosocial wellbeing. There were no physiological parameters, access to health care, and desirability contributing to their health behaviour, such as smoking. Less affordability of purchasing a weighing machine. Matching was not done with confounders or age, gender, and other variables. ECG, Echo, scans and blood tests were not considered in this study.

\section{Conclusion}

Chronic heart failure affects the adult's adherence to self-care and activities of daily living. Nurse-led cardiac rehabilitation guidelines and standard help to improve adherence and healthcare behaviours among adults with chronic heart failure to improve their quality of life. NLCRP is important for adults to improve their self-care and self-management while adhering and complying with the treatment and health care. Social innovation strategies are needed to improve physical, mental, psychosocial, and emotional needs for adults with complexity of illness and for continuity of care. In conclusion, nurse-led cardiac rehabilitation program had increased efficacy with patient reported outcomes like adherence and healthcare behavours. Monitoring weight, physical activity, and lifestyle modifications were critical elements of NLCRP for participants with chronic heart failure. This paper highlights the importance of cardiac care, active living and healthy lifestyles.

\section{Implications}

The nurse-led cardiac rehabilitation program can be delivered to patients with chronic heart failure in the hospitals, community, and home settings. The cardiac rehabilitation virtual educational video can be used to educate and instruct patients with chronic heart failure. Goal setting and commitment to change are important aspects of cardiac rehabilitation programs to maximize physical, psychological, and social functioning. Cardiac nurses could encourage tailored and individualized sessions to learn about adherence and healthcare behaviour strategies. Practice nurses could involve family members to enhance their knowledge of adherence and practice of healthcare behaviors to improving quality of life and health promoting behaviours. Nurses could schedule family and patient engagement in cardiac rehabilitation programs to pave the way for developing a cost-effective framework for home care. Clinical nurses could encourage group sessions to learn about adherence strategies to follow systematically, continuously, and daily. Utilizing this nurse-patient communication could involve family members to enhance their knowledge on adherence and healthcare behaviours. Nurse-led cardiac rehabilitation program can contribute to better transitional care for adults and families in the community. The findings have been disseminated with the decision makers in healthcare and policy makers for preparing cardiac rehabilitation guidelines and implementation of care. Telehealth and rapid access clinics will support continuity of care and increase participation of patients. Further research studies can be conducted using a randomized control trial focused on improving person centered care through nurses in the home and community care. Further studies can be conducted using mixed approaches to assess the barriers and facilitators towards efficacy in cardiac rehabilitation. Multicenter studies can be conducted to assess the self-efficacy, adherence and healthcare behaviors in cardiac rehabilitation of patients and family support in home care.

\section{Authors' institutional affiliation}

Porkodi Arjunan (PA) and Melba Sheila D'Souza (MSD) has made substantial contribution to conception and design, acquisition of data, analysis, and interpretation of data findings; been involved in drafting the manuscript, revising it critically for important intellectual content; giving final approval of the version to be published and agreed to be accountable for all aspects of the work related to accuracy and integrity of the work.

\section{Funding sources}

This work was supported by the Sri Ramachandra Institute of Higher Education and Research, IEC/07/21/Nov/2018. The sponsors played no role in the design, execution, analysis, data interpretation, writing reports or decision to submit the paper for publication.

\section{Code of ethics in publishing}

The study has been approved by the Sri Ramachandra Institute of Higher Education and Research, IEC/07/21/Nov/2018.

\section{Copyright Transfer Agreement}

We agree to the copyright of the Author Licensing Service, Journal publishing agreement and all the authors will sign the Copyright Transfer Agreement.

\section{Submission declaration}

This article has not been submitted to any journal and the work described has not been published previously in any form and is not under consideration of publication elsewhere.

\section{Language}

This paper was edited for grammar and communication by a native English academic and linguistic expert.

\section{Submission checklist}

We have adhered to the journal standards, scope, and author guidelines. We have uploaded Cover letter, Abstract, Main text and References, Tables, Figures and Title Page (Separate).

\section{Declaration of competing interest}

We declare there is no conflict of interest and no vested interests. The views expressed in this study do not necessarily represent the views of the individuals, institutes, and hospitals. 


\section{Acknowledgements}

I would like to acknowledge the support of the participants, validators, department, and hospital.

\section{References}

1 Cheng S, Vasan RS. Advances in the epidemiology of heart failure and left ventricular remodeling. Circulation. 2011 Nov 15;124(20):e516-e519.

2 van der Wal MH, Jaarsma T, van Veldhuisen DJ. Non-compliance in patients with heart failure; how can we manage it? Eur J Heart Fail. 2005 Jan;7(1):5-17.

3 Mozaffarian D, Benjamin EJ, Go AS, et al. American heart association statistics committee; Stroke statistics subcommittee. Heart disease and stroke statistics-2016 update: a report from the American Heart Association. Circulation. 2016 Jan 26;133 (4): $238-60$

4 Hu SS, Kong LZ, Gao RL, et al. Outline of the report on cardiovascular disease in China. Biomed Environ Sci. 2012 Jun 1;25(3):251-256, 2010.

5 Pillai HS, Ganapathi S. Heart failure in South Asia. Curr Cardiol Rev. 2013 May 1;9 (2):102-111.

6 Lam CS. Heart failure in Southeast Asia: facts and numbers. ESC Heart Fail. 2015;2: 46-49.

7 Heidenreich PA, Lewis WR, LaBresh KA, Schwamm LH, Fonarow GC. Hospital performance recognition with the Get with the Guidelines Program and mortality for acute myocardial infarction and heart failure. Am Heart J. 2009 Oct 1;158(4): $546-553$.

8 Lam CS, Teng TH, Tay WT, et al. Regional, and ethnic differences among patients with heart failure in Asia: the Asian sudden cardiac death in heart failure registry. Eur Heart J. 2016 Nov 1;37(41):3141-3153.

9 Nieminen MS, Brutsaert D, Dickstein K, et al. EuroHeart Failure Survey II (EHFS II): a survey on hospitalized acute heart failure patients: description of population. Eur Heart J. 2006 Nov 1;27(22):2725-2736.

10 Ushigome R, Sakata Y, Nochioka K, Miyata S, Miura M, Tadaki S, Yamauchi T, Sato K, Onose T, Tsuji K, Abe R, Oikawa T, Kasahara S, Takahashi J, Shimokawa H. CHART-2 Investigators. Temporal trends in clinical characteristics, management and prognosis of patients with symptomatic heart failure in Japan - report from the CHART Studies. Circ J. 2015;79(11):2396-2407. https://doi.org/10.1253/circj.CJ15-0514. Epub 2015 Sep 10. PMID: 26356834.

11 Burke MA, Katz DH, Beussink L, et al. Prognostic importance of pathophysiologic markers in patients with heart failure and preserved ejection fraction. Circulation: Heart Fail. 2014 Mar;7(2):288-299.

12 Brunner LS, Smeltzer SCOC, Bare BG, Hinkle JL, Cheever KH. Brunner \& Suddarth's Textbook of Medical-Surgical Nursing. Philadelphia: Wolters Kluwer Health/Lippincott Williams \& Wilkins; 2010.

13 D'Souza MS, Labrague LJ, Karkada SN, Kamble P. Relationship between sociodemographic, clinical factors, and quality of life in adults living with diabetic nephropathy. Clinical Epidemiology and Global Health. 2020 Jun 1;8(2):343-349.

$14 \mathrm{Col} \mathrm{N}$, Fanale JE, Kronholm P. The role of medication noncompliance and adverse drug reactions in hospitalizations of the elderly. Arch Intern Med. 1990 Apr 1;150(4): 841-845.

15 D'Souza MS, Ruppert SD, Parahoo K, et al. Foot care behaviors among adults with type 2 diabetes. Primary care diabetes. 2016 Dec 1;10(6):442-451.

16 Dracup K, Baker DW, Dunbar SB, et al. Management of heart failure: II. Counseling, education, and lifestyle modifications. Jama. 1994 Nov 9;272(18):1442-1446.

17 Happ MB, Naylor MD, Roe-Prior P. Factors contributing to rehospitalization of elderly patients with heart failure. J Cardiovasc Nurs. 1997 Jul 1;11(4):75-84.

18 Bennett SJ, Milgrom LB, Champion V, Huster GA. Beliefs about medication and dietary compliance in people with heart failure: an instrument development study. Heart Lung. 1997 Jul 1;26(4):273-279.

19 Schweitzer RD, Head K, Dwyer JW. Psychological factors and treatment adherence behavior in patients with chronic heart failure. J Cardiovasc Nurs. 2007 Jan 1;22(1): 76-83.
20 Rubin DJ, Donnell-Jackson K, Jhingan R, Golden SH, Paranjape A. Early readmission among patients with diabetes: a qualitative assessment of contributing factors. J Diabetes Complicat. 2014 Nov 1;28(6):869-873.

21 Riegel B, Jaarsma T, Stromberg A. Theory of self-care of chronic illness. Middle Range Theory Nursing. 2018 Mar 10;35:341-353.

22 Moser DK, Dickson V, Jaarsma T, Lee C, Stromberg A, Riegel B. Role of self-care in the patient with heart failure. Curr Cardiol Rep. 2012 Jun 1;14(3):265-275.

23 DSouza MS, Al Salmi NM. Self-efficacy impact adherence in diabetes mellitus. Clinical Research in Diabetes and Endocrinology. 2018;1(2):1-4.

24 Authors/Task Force Members, Dickstein K, Vardas PE, Auricchio A, et al. 2010 Focused Update of ESC Guidelines on device therapy in heart failure: an update of the 2008 ESC Guidelines for the diagnosis and treatment of acute and chronic heart failure and the 2007 ESC guidelines for cardiac and resynchronization therapy Developed with the special contribution of the Heart Failure Association and the European Heart Rhythm Association. Europace. 2010 Nov 1;12(11):1526-1536.

25 Jaarsma T, Halfens R, Tan F, Abu-Saad HH, Dracup K, Diederiks J. Self-care, and quality of life in patients with advanced heart failure: the effect of a supportive educational intervention. Heart Lung. 2000 Sep 1;29(5):319-330.

26 Hunt SA. ACC/AHA 2005 guideline update for the diagnosis and management of chronic heart failure in the adult: a report of the American college of cardiology/ American heart association task force on practice guidelines (writing committee to update the 2001 guidelines for the evaluation and management of heart failure). J Am Coll Cardiol. 2005 Sep 20;46(6):e1-82.

27 Yancy CW. Comprehensive treatment of heart failure: state-of-the-art medical therapy. Rev Cardiovasc Med. 2005 Feb 20;6(S2):43-57.

28 Lindenfeld J, Albert NM, Boehmer JP, et al. HFSA 2010 comprehensive heart failure practice guideline. J Card Fail. 2010 Jun 1;16(6):e1-194.

29 Austin J, Williams R, Ross L, Moseley L, Hutchison S. Randomised controlled trial of cardiac rehabilitation in elderly patients with heart failure. Eur J Heart Fail. 2005 Mar;7(3):411-417.

30 van Der Wal MH, Jaarsma T, Moser DK, Veeger NJ, van Gilst WH, van Veldhuisen DJ. Compliance in heart failure patients: the importance of knowledge and beliefs. Eur Heart J. 2006 Feb 1;27(4):434-440.

31 van der Wal MH, Jaarsma T. Adherence in heart failure in the elderly: problem and possible solutions. Int J Cardiol. 2008 Apr 10;125(2):203-208.

32 D'Souza MS, Karkada SN, Labrague LJ, Ammouri AA. How do multi-modality strategies affect outcomes in T2D using a randomized control trial? Clinical Epidemiology and Global Health. 2019 Dec 1;7(4):578-585.

33 van der Wal MH, Jaarsma T, Moser DK, van Gilst WH, van Veldhuisen DJ. Qualitative examination of compliance in heart failure patients in The Netherlands. Heart Lung. 2010 Mar 1;39(2):121-130.

34 Hasanpour-Dehkordi A, Khaledi-Far A, Khaledi-Far B, Salehi-Tali S. The effect of family training and support on the quality of life and cost of hospital readmissions in congestive heart failure patients in Iran. Appl Nurs Res. 2016 Aug 1;31:165-169.

35 D'Souza MS, Karkada SN, Parahoo K, Venkatesaperumal R, Achora S, Cayaban AR. Self-efficacy, and self-care behaviours among adults with type 2 diabetes. Appl Nurs Res. 2017 Aug 1;36:25-32.

36 Cajanding RJ. The effectiveness of a Nurse-Led cognitive-behavioral therapy on the quality of life, self-esteem and mood among Filipino patients living with heart failure: a randomized controlled trial. Appl Nurs Res. 2016 Aug 1;31:86-93.

37 Jaarsma T, van der Wal MH, Lesman-Leegte I, et al. Effect of moderate or intensive disease management program on outcome in patients with heart failure: coordinating Study Evaluating Outcomes of Advising and Counseling in Heart Failure (COACH). Arch Intern Med. 2008 Feb 11;168(3):316-324.

38 Lupón J, González B, Santaeugenia S, et al. Prognostic implication of frailty and depressive symptoms in an outpatient population with heart failure. Revista Española de Cardiología (English Edition). 2008 Jan 1;61(8):835-842.

39 Tevik K, Thürmer H, Husby MI, de Soysa AK, Helvik AS. Nutritional risk screening in hospitalized patients with heart failure. Clin Nutr. 2015;34(2):257-264.

40 McKelvie RS, Teo KK, McCartney N, Humen D, Montague T, Yusuf S. Effects of exercise training in patients with congestive heart failure: a critical review. J Am Coll Cardiol. 1995 Mar 1;25(3):789-796.

41 D'Souza MS, Venkatesaperumal R, Walden J. Nurse-led intervention to improve the quality of life among adults with type 2 diabetes undergoing hemodialysis. The Malaysian Journal of Nursing (MJN). 2018 Jul 2;10(1):85-95. 